\title{
Smart Irrigation and Temperature Control for a Greenhouse System
}

\author{
${ }^{*} P$ Abinaya ${ }^{1}, P$ Swathika ${ }^{2}$ \\ ${ }^{l}$ Assistant Professor, Department of CSE, Mepco Schlenk Engineering College, Sivakasi, \\ Tamilnadu, India \\ abinayap@mepcoeng.ac.in \\ ${ }^{2}$ Asssitant Professor, Department of AIDS, Mepco Schlenk Engineering College, Sivakasi, \\ Tamilnadu, India \\ swathikap@mepcoeng.ac.in
}

\begin{abstract}
Now a days it's a great challenge for the farmers to irrigate the crops in a correct time. This project is designed with the aim to facilitate the farmer or gardener to engage in green house systems and to improve agricultural technology. In order to reduce continuous monitoring of the soil parameters, excess time consumption for the farmers and excessive usage of water, "Smart irrigation and temperature control for a greenhouse system" has been developed. There are two different ways to irrigate the land namely traditional irrigation methods and modern irrigation methods.
\end{abstract}

Keywords: Green House, Smart Irrigation, Temperature control and agriculture technology

\section{INTRODUCTION}

The increased agriculture productivity through irrigated land is developed in arid and sub-humid zones. Agriculture has started to compete for water use with industries and other sectors. This increasing demand along with increments in water and energy costs have made it necessary to develop new technologies for the adequate management of water. The intelligent use of water for crops requires understanding of evapotranspiration processes and use of efficient irrigation methods. Unfortunately, often less than half of water applied is used by the crop-irrigation water may be lost through runoff, which may also cause damaging soilerosion. The main objective of irrigation is to provide plants with sufficient water to prevent stress that may increase the yield.

Muangprathub, J [1] proposed a system that ideally watering the crops in the agricultural field based on a wireless sensor network. They developed a system to control the watering power to the crops using sensor via web application or smart phone. Federico Capello [2] proposed the monitoring system to monitor and manage the agrifoods products based on Industrial Internet of Things(IIoT). Using IIoT, the respective values have been generated to monitor the agrifoods. The need of monitoring the agrifoods is to find the contamination stage. Ke-tao Chen [3] anticipated a system that was used to monitor the soil temperature and moisture. The system is being comprised of three main parts monitoring module, gateway module and system module. In this work, the soil moisture and temperature are measured in the depths of $10 \mathrm{~cm}, 20 \mathrm{~cm}, 30 \mathrm{~cm}$ and $40 \mathrm{~cm}$. Lukas et. al, [4] proposed a system that monitored the water level of crops ubiquitously using the Raspberry Pi.

The green house system provides a better environment for the crops by maintaining proper temperature, moisture and humidity levels .This system helps the crops to grow in a healthy condition which leads to increased productivity. Green house agriculture protects the crops from various environmental and atmospheric agents with suitable and appropriate equipments by simultaneously controlling the crops climate which further leads to increased quality of the crops and allows a way for higher yield. Amount of water content present in the soil is 
termed as moisture and this factor determines the sustainability of the land for the growth of crops. Plants grown in greenhouse environment promotes faster growth and increased quality as the crops are maintained in a proper temperature controlled green house environment with are suitable and necessary for the growth of crops.

M.A.Fourati et. al,[5] presented a system that is aimed to understand the monitoring webbased decision support system that is being used to schedule the irrigation process in the circumstance of developing countries. The farmers are being supported by this system to reorganize the agriculture land using GIS maps and give the information required.The Smart irrigation and temperature control for a greenhouse system will control the watering of crops by monitoring the necessary conditions like soil moisture, temperature and humidity to sense the current nature of the soil. By collecting the soil moisture, watering of crops can be controlled. When the moisture value is low it denotes that the soil is dry and it needs to be watered and so the motor is switched on and when sufficient water is pumped into the field then again the motor is switched off. By controlling the temperature value, the temperature level can be controlled that is when the temperature is too high then the cooling fan is on which reduces the current temperature which helps the user to cultivate the crops even in hot climatic regions. Qingzu et. al, [6] proposed a simulated system that monitors the famine of the crop. Based on the values obtained from the previous module, it schedules the irrigation for the crop. Abinaya [7] proposed a system that monitors the healthcare of elderly people or disease affected persons through the IoT devices. The collected data is converted into OWL format for getting the best care for elderly people in terms of cause, effect, medicines for the disease. Vinoth [8] proposed a work that focuses on the IP addressing of the IoT devices for the identification of the object.

This project is designed with the aim to facilitate the farmer or gardener to engage in green house systems and to improve agricultural technology.In order to reduce continuous monitoring of the soil parameters, excess time consumption for the farmers and excessive usage of water, "Smart irrigation and temperature control for a greenhouse system" has been developed.

Smart irrigation and temperature control for a greenhouse system is a IOT solution to monitor and irrigate the crop. It reduces the burden of monitoring [9] the crops regularly and watering them. The Internet of things (IOT) is the inter-networking of physical devices also referred connected device and smart device vehicles, building, and other items -embedded with electronics, software, and exchange data. A sensor, actuators and network connectivity that enables these objects to collect and exchange data. A sensor is device which detects or measure the physical property and records indicates or otherwise responds to it. Soil moisture sensor measure the volumetric water content in the soil. The DHT11 sensor is basic, ultralowcost Temperature and humidity sensor. It uses a capacitive humidity sensor and a thermistor to measure the surrounding air, and splits out a digital signal on the data pin.

\section{Methodologies}

\subsection{Existing system}

This irrigation system consists of DHT11 and hygrometer sensor which is used to measure the temperature, humidity and moisture values of the soil and it also consists of the nodemcu with the inbuild wifi shield which is used to store the data to the database. Android application is developed to display these values and to control the motor. 
Initially the values of temperature, humidity and moisture are collected from the soil by using the DHT11 and hygrometer sensor then these values are stored in the database by using the nodemcu with the inbuild wifi shield which is used to transfer the data from arduino to database.

Then the values are retrieved in android, this android application also has provision to view the values of soil parameters and then to control the motor that is when the moisture value is greater than the threshold value then the user can able to on the motor then if the moisture value is lesser than the threshold value then the motor is switched off.

\section{Proposed system}

This irrigation system consists of DHT11 and hygrometer sensor which is used to measure the temperature, humidity and moisture values of the soil and it also consists of the nodemcu with the inbuild wifi shield which is used to store the data to the firebase. Android application is developed to display these values and to control the motor and the cooling fan.

Initially the values of temperature, humidity and moisture are collected from the soil by using the DHT11 and hygrometer sensor then these values are stored in the cloud firebase by using the nodemcu with the inbuild wifi shield which is used to transfer the data from arduino to cloud firebase.

Then the values are retrieved in android, this android application also has provision to view the values of soil parameters and then to control the motor that is when the moisture value is greater than the threshold value then alert is send to the user then the user can able to on the motor then if the moisture value is lesser than the threshold value then the motor is switched off ,similarly when the temperature value is greater than the threshold value that is when temperature is too high then the cooling fan is switched on then when the temperature value is low then the cooling value is switched off. Thus this method is used to minimize the wastage of water.

Steps involved in smart irrigation and temperature control for a greenhouse system are the soil parameters like temperature, humidity and moisture are collected from the soil, collected data are then fed into the firebase (Real time database) for remote access, Android application is developed, the current values of soil parameters like temperature, humidity, moisture is displayed by using this application, when the moisture value is greater or less than threshold value, alert is sent through the application, farmers can able to on/off the motor, when the temperature value is greater or less than the threshold value, alert is sent through the application and farmers can on/off the cooling fan.

\subsubsection{System Flow Diagram}




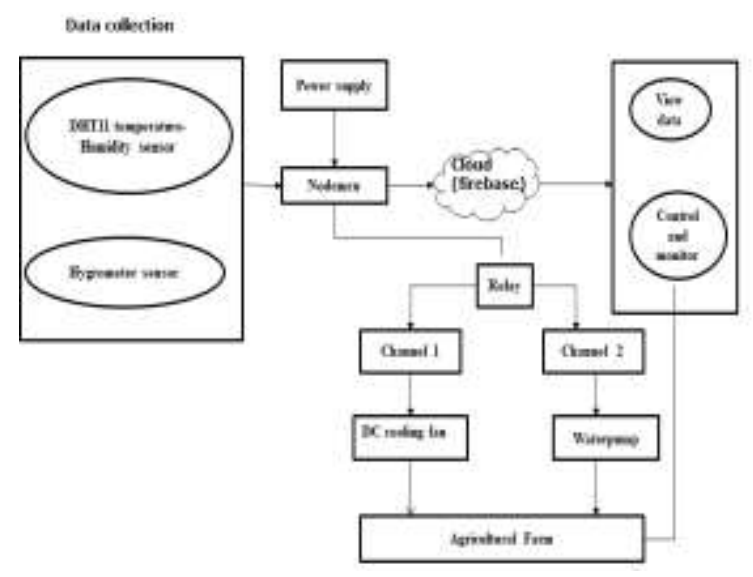

Figure 1 System flow Diagram

Soil moisture content is sensed by the soil moisture sensor, temperature and humidity is sensed by the DHT11 sensor. The collected sensor values are sent to the cloud firebase by using the 17 ESP8266 wifi module which is embedded in nodemcu. From the obtained value the alert is send to the farmers thus the motor and the cooling fan is controlled.

\subsubsection{Data Acquisition}

In the project, soil moisture sensor (hygrometer), temperature - humidity sensor (DHT11) and Wi-Fi module are used. The real time data are sensed by using the sensors and are sent to cloud (Firebase). For transferring the data to cloud ESP8266 Wi-Fi module is used.

\subsubsection{Data sent to the firebase}

In order to view the data from remote location, the data are sent to the cloud Firebase and the values are updated for every 30 minutes.

\subsubsection{View data through mobile application.}

In order to promote the display of data such as temperature, humidity and moisture to the user, Android Studio is used.

\subsubsection{Control of watering based on moisture value}

The control of watering by the user is done by using the mobile application (ON/OFF) with the help of water pumping motor. By using this method water can be used efficiently which leads to less usage of water. The moisture value is displayed automatically 20 whenever the application is opened in the mobile. By this the user can view the real time condition of the soil moisture from any distant location. Once the moisture value reaches the lower threshold value, the alert message is sent to the user to turn $\mathrm{ON}$ the pumping motor. The user by viewing the alert and by checking the necessity of water to the crops can decide whether to water the plants. Besides if the moisture value reaches the upper threshold value, the alert message is sent to the user to turn OFF the pumping motor. The user by viewing the alert and checking the moisture level can decide whether to turn OFF the motor. The water requirement will not be same for all the plants it differs from one plant to another. . Hence the moisture value differs from one plant to another.

\subsubsection{Control of temperature based on DHT11 temperature value}


The control of temperature by the user is done by using the mobile application (ON/OFF) with the help of DC cooling fan. By using this method, the moderate climate crops can be made to grow in extreme hot regions as the temperature can be controlled by using the cooling fan which leads to increased crop production and promotes good quality. The temperature value is displayed automatically whenever the application is opened in the user's mobile. By this the user can view the real time condition of the soil temperature from any distant location. Once the temperature value reaches the lower threshold value, the alert message is sent to the user to turn $\mathrm{ON}$ the cooling fan. The user by viewing the alert and by checking temperature requirement to the crops can decide whether to use the cooling fan. Besides if the moisture value reaches the upper threshold value, the alert message is sent to the user to turn OFF the cooling fan. The user by viewing the alert and checking the temperature level can decide to turn OFF the cooling fan.

\section{Results and Discussion}

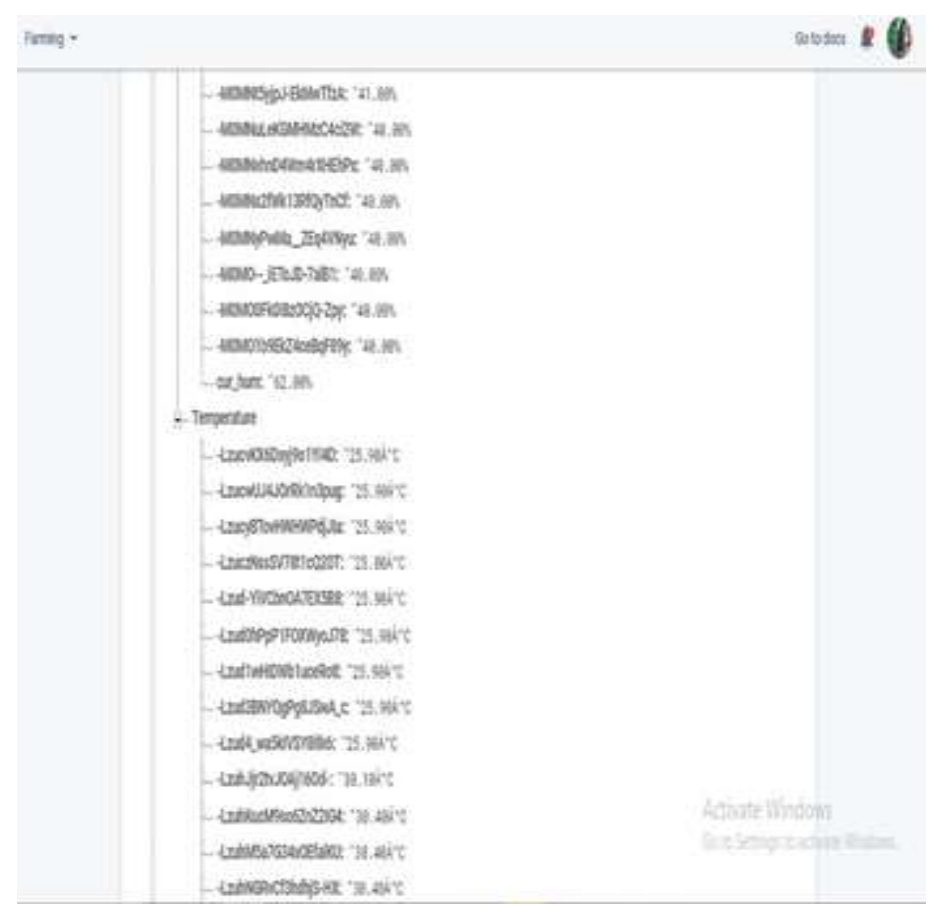

Figure 2 Firebase displaying Temperature values

This displays the temperature value from arduino uno, the new values from arduino uno are also updated frequently. 


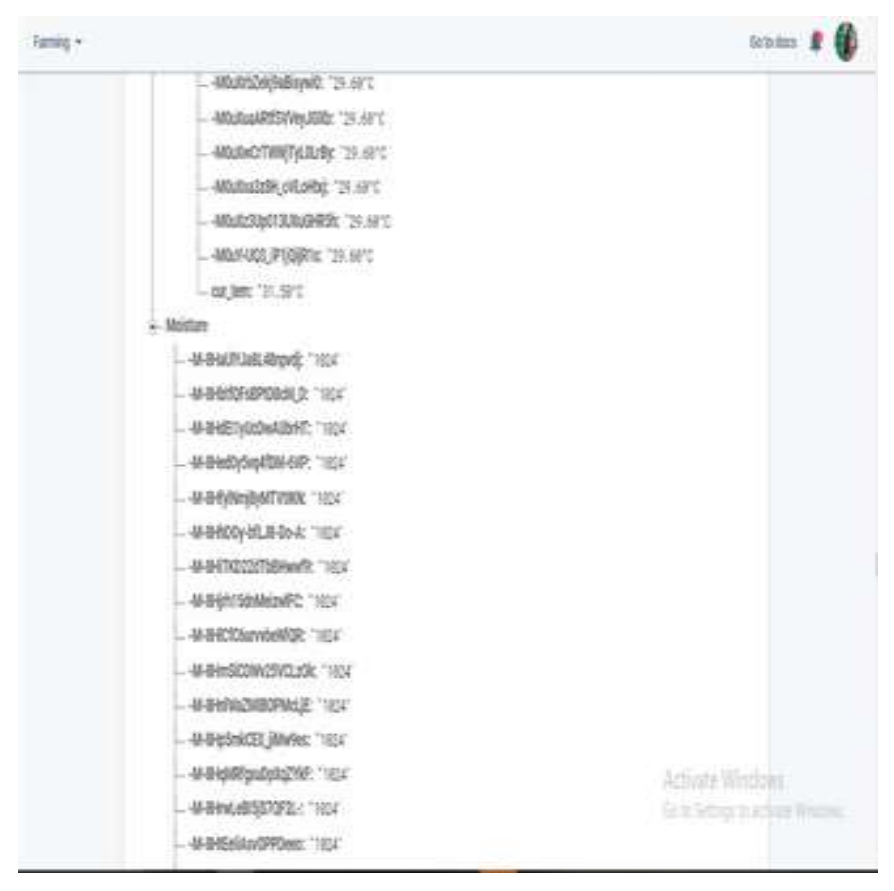

Figure 3 Firebase displaying Moisture values

This displays the moisture value from arduino uno, the new values from arduino uno are also updated frequently.

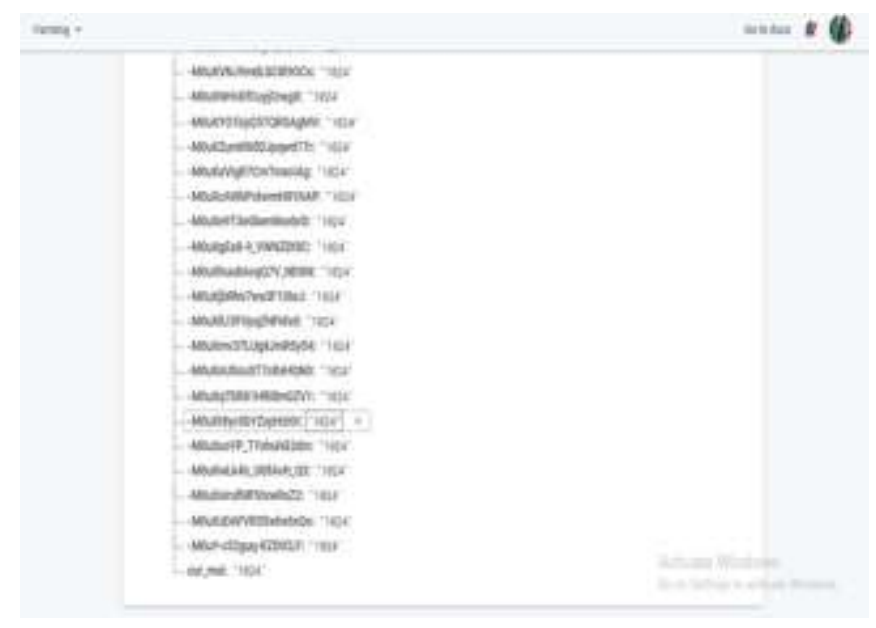

Figure 4 Firebase displaying Humidity values

This displays the humidity value from arduino uno, the new values from arduino uno are also updated frequently. 


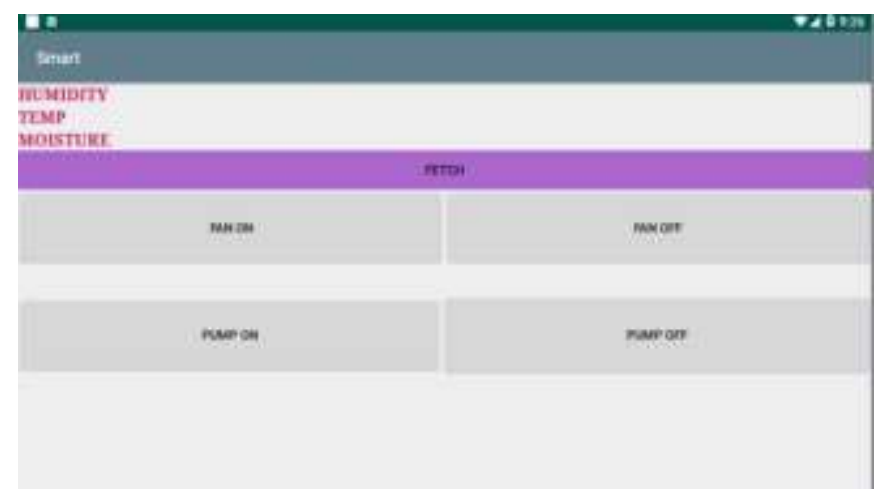

Figure 5 Android studio output

Android studio output will be displayed on the users phone and thus on/off of the fan and the pump can be controlled. It also displays the current value of humidity, temperature and moisture thus users can also be updated with all these soil parameters.

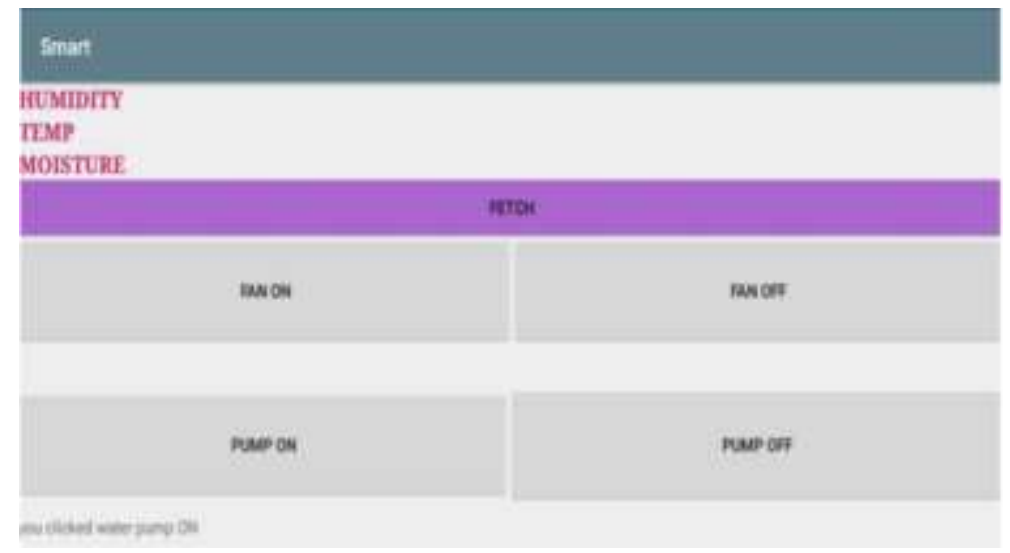

Figure 6 Switching on/off water pump

The above figure shows the output which will be displayed on the users phone when the user click the pump on. It also displays the current value of humidity, temperature and moisture thus users can also be updated with all these soil parameters.

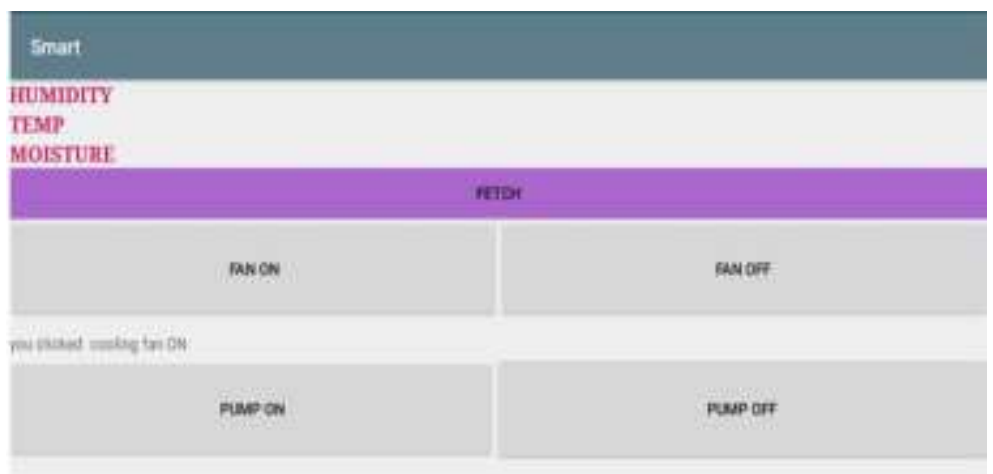

Figure 6 Switching on of cooling fan

The above figure shows the output which will be displayed on the users phone when the user click the cooling fan on. It also displays the current value of humidity, temperature and moisture thus users can also be updated with all these soil parameters 


\section{CONCLUSION AND FUTURE WORK}

This system includes a working hardware prototype and an android application for irrigation and temperature control. The wireless transmission is achieved using WiFi. The data are retrieved successfully from cloud Firebase, which is used for monitoring purpose. The mobile application paves the way to view the current values of the soil parameters even from remote locations and provides a user interface. By implementing this system we can improve the traditional way of agriculture and establishment of greenhouse system in different regions of India

In future this design will be enabling the user to select the crop and thus the moisture, temperature and humidity content for that particular crop can be viewed and then the controlled based on the threshold value of the moisture and temperature. Further the system can perform data analysis, based on the crops selected and the threshold value is changed automatically.

\section{REFERENCES}

1. Jirapond Muangprathub, Nathaphon Boonnam, Siriwan Kajornkasirat, Narongsak Lekbangpong, Apirat Wanichsombat, Pichetwut Nillaor.,2019 IoT and agriculture data analysis for smart farm, In: Computers and Electronics in Agriculture 156(2019) 467-474.

2. Capello, F., Toja, M., Trapani, N., 2016. A real-time monitoring service based on industrial internet of things to manage agrifood logistics. In: 6th International Conference on Information Systems, Logistics and Supply Chain, pp. 1-8.

3. Chen, K.T., Zhang, H.H., Wu, T.T., Hu, J., Zhai, C.Y., Wang, D., 2014. Design of monitoring system for multilayer soil temperature and moisture based on WSN. In: International Conference on Wireless Communication and Sensor Network (WCSN). IEEE, Wuhan, pp.425-430. https://doi.org/10.1109/WCSN.2014.9.

4. Lukas, Tanumihardja, W.A., Gunawan, E., 2015. On the application of IoT: monitoring of troughs water level using WSN. In: Conference on Wireless Sensors (ICWiSe). IEEE, pp.58-62.

5. Fourati, M.A., Chebbi, W., Kamoun, A., 2014. Development of a web-based weather station for irrigation scheduling. In: Information Science and Technology (CIST), 2014 Third IEEE International Colloquium in IEEE, pp. 37-42.

6. Luan, Q., Fang, X., Ye, C., Liu, Y., 2015. An integrated service system for agricultural drought monitoring and forecasting and irrigation amount forecasting. In: 23rd International Conference on Geoinformatics. IEEE, pp. 1-7.

7. Abinaya, Vinoth Kumar, Swathika, "Ontology Based Public Healthcare System in Internet of Things (IoT)," Procedia Computer Science., vol. 50, pp. 99- 102, Oct. 2015.

8. B. Vinoth Kumar, M. Ramaswami, P. Swathika, and P. Abinaya, "IPv6 based Patient Monitoring Architecture for Future Healthcare Application" International Journal of Computer Science and Information Security Vol. 14, ISSN 1947-5500, Oct. 2016.

9. Abinaya, P; Aruna; Dharini, Anusha; Devi, Aruna; Devi, Abarna, "Intrusion Detection in Agriculture Field Based on Internet of Things (IoT)", Journal of Computational and Theoretical Nanoscience, Vol. 15, Numbers 6-7, pp. 19961998(3), June 2018. 